\title{
Sara Malvar: modernidad, manifiesto y poemas pintados
}

\section{Patricio Lizama A.*}

\section{Resumen}

En este trabajo analizamos las diferentes modalidades de inserción de los artistas plásticos chilenos en la modernidad parisina a comienzos del siglo XX; luego, nos detenemos en el caso de Sara Malvar, artista que se vincula con los actores centrales de la vanguardia en Francia y que redefine su posición dentro de su matrimonio. Por último, analizamos la actividad de Malvar en París y su aporte en dos poemas pintados de Huidobro.

Palabras clave: viaje a París, manifiesto, poemas pintados, molino, paisaje.

\section{Sara Malvar: Modernity, Manifest and Painted Poems}

\begin{abstract}
In this paper we analyze the different ways of insertion of Chilean plastic artists in Parisian modernity at the beginning of the 2oth century; then, we stop in the case of Sara Malvar, an artist who is linked to the central actors of the vanguard in France and who redefines her position within her marriage. Finally, we analyze the activity of Malvar in Paris and his contribution in two painted poems by Huidobro.
\end{abstract}

Keywords: Trip to Paris, manifesto, painted poems, mill, landscape.

El presente trabajo es parte del proyecto Fondecyt Regular $N^{\circ} 1150535$, "Poema en prosa y modernidad en Chile: 1888-1945”, del cual el autor de este artículo es responsable.

2 Chileno. Doctor en Literatura Hispanoamericana. Universidad Estatal de Nueva York, Stony Brook. Académico de la Pontificia Universidad Católica de Chile, Santiago, Chile.plizama@uc.cl 
En Umbral, esa obra desmesurada e inclasificable, Juan Emar recuerda al Grupo Montparnasse, que surge en el campo plástico chileno en octubre de 1923, señalando que hizo exposiciones e invitó a pintores cuyas tendencias estaban de acuerdo con las del Grupo. En una de estas muestras, el "Salón de Junio de 1925. Exposición de Arte Libre organizada y auspiciada por el diario La Nación", Sara Malvar participa como artista independiente y presenta trece pinturas -naturalezas muertas, retratos, dibujos- y seis gouaches que son copias de obras de Pablo Picasso hechas por ella durante su estadía en París'.

El trabajo visual de Sara Malvar se desarrolla en las décadas del diez y del veinte en Chile, España y Francia. Ella se presenta en los salones oficiales de 1916 y 1919 en Santiago; en 1916 viaja a España, casada con el pintor chileno José Backhaus, su profesor en la academia santiaguina; reside en París entre 1921 y 1923, capital donde realiza obras vinculadas a las concepciones cubistas, colabora en la composición de los poemas pintados de Vicente Huidobro y hace copias de creaciones cubistas. En esta misma época, en 1922 en París, queda viuda, sufre una depresión severa y a finales de 1923 regresa a Chile.

En este trabajo analizamos las formas de inserción que adoptan los pintores chilenos al viajar a París a comienzos del siglo XX; luego, estudiamos cómo Malvar se vincula con las nuevas tendencias artísticas europeas y, por último, analizamos la actividad plástica de Malvar en la capital francesa, en particular, su trabajo con los poemas pintados "Molino" y "Paisaje" de Vicente Huidobro.

\section{El viaje a París: modernidad y arte}

Ser modernos es "encontrarnos en un entorno que nos promete aventuras, poder, alegría, crecimiento, transformación de nosotros y del mundo y que, al mismo tiempo, amenaza con destruir todo lo que tenemos, todo lo que sabemos, todo lo que somos" (Berman 1). El sujeto de la modernidad periférica que se traslada a la modernidad central vive una experiencia compleja, pues debe enfrentarse a un mundo pleno de posibilidades, percibido como un incesante flujo de situaciones y acontecimientos

\footnotetext{
Su nombre completo es Sara María Camino Malvar. En sus comienzos firma como Sara María Camino y también a veces como Sara Camino; a partir de 1923, en las "Notas de Arte" de La Nación, como Sara Malvar.
} 
siempre nuevos y, a la vez, a un mundo lleno de riesgos y dificultades, dualidad que es vivida "con ambigüedad y angustia, como autorrealización y destrucción de uno mismo” (Brunner 180).

Estas vivencias contradictorias están en la base de lo experimentado por el artista sudamericano que se forma en la academia y llega a París. José Backhaus, Sara Malvar, los pintores nacionales distanciados de su cultura de origen, con una enseñanza plástica alejada de las tendencias emergentes, enfrentan a una metrópolis cosmopolita y sus reacciones en la capital francesa van desde la apertura, el aprendizaje y la apropiación, hasta el desconcierto, el rechazo y la inmovilidad. Para unos, París es una ciudad compleja, abierta, móvil, con un campo cultural autónomo y “libertades excepcionales de expresión” que les resulta un espectáculo deslumbrante y lleno de novedades y desafíos: "promete aventuras, poder, alegría, crecimiento, transformación de nosotros y del mundo" (Berman 1). Para otros, la capital francesa aparece como una pesadilla que los desorienta y los inquieta porque su vida moderna, sus diversos mundos y su variedad de propuestas artísticas cuestionan las creencias y certezas artístico-culturales, el modelo de artista y los modos de comportamiento, terminando por generar angustia y reclusión.

El desconcierto ante el movimiento vanguardista es visible entre los pintores del grupo de Los Diez que llegan a París en 1922, un año después que la pareja Backhaus-Malvar. Manuel Magallanes Moure en su primera noche en la capital francesa, a fines de enero de 1922, visita uno de los templos del barrio Montparnasse, el café “La Rotonde", y su relato da cuenta del cosmopolitismo del lugar, la múltiple fisonomía de los asistentes y el peculiar maquillaje de las mujeres. El artista chileno considera que se encuentra ante "gente espeluznante", y por ello, "medio asfixiado, sintiendo de pronto la necesidad de despertar de aquella pesadilla, le dice a Alberto Ried, [otro integrante de Los Diez]: ¡vámonos!” (Díaz, Bohemios 222).

La visión de los "cuadros ultramodernistas" que cuelgan en la pared de "La Rotonde" resulta una nueva pesadilla para Magallanes Moure. Su carta devela con claridad su completo asombro: "paisajes inverosímiles, de colores detonantes y formas desquiciadas; naturalezas muertas, frutas como recortadas y pegadas en un plato colocado verticalmente; figuras que quisieron ser humanas y resultaron habitantes de Marte o de la Luna" (Díaz, Bohemios 222). Las escenas y los personajes son insólitos para el artista decimal, resultan de gran extrañeza, de una imaginación 
impensada y no caben dentro de sus parámetros artísticos; la forma de representar y la descomposición de las figuras tampoco logra asimilarlas, pues exceden las visiones por él conocidas. No es casual que Magallanes Moure señale que las pinturas son una "pesadilla de líneas atormentadas y de colores dolorosos como gritos despavoridos" (Díaz, Bohemios 222). La visita a "La Rotonde" es una sinécdoque del viaje de varios artistas chilenos a la modernidad central en los años diez y veinte.

La misma extrañeza experimenta Alberto Ried, quien tiene la necesidad de entender y explicitar la novedad que lo cuestiona. En carta escrita en París en junio de 1922 a Pedro Prado, otro escritor, pintor, con estudios de arquitectura y líder de Los Diez, le comenta:

La perspectiva no existe sino como un defecto, o una imperfección visual. Luego, o ergo, una figura de mujer, pongamos por caso, que antes se diseñaba de perfil, aparece hoy de perfil pero con el lado que creíamos oculto, bien plantado al lado, ... sí, al lado del costado que se ve! ¿Me comprendes? No sé si retengo bien la silueta asombrosa que vi, pero es algo así. (Díaz, Bohemios 243)

Ried, aunque asombrado por lo que ve, explica los cambios operados en la plástica. La contemplación de las obras cubistas y la ausencia de perspectiva desde un solo punto de vista, los nuevos retratos que ofrecen una visión múltiple del objeto, la perspectiva móvil, la representación de lo sucesivo y de lo simultáneo, son novedades que Ried recién aprecia.

Los pintores más jóvenes pertenecientes a la generación de Sara, los del círculo de croquis que son discípulos de Juan Francisco González, llegan a Paris a confirmar lo aprendido en Chile, a estudiar los cuadros del canon plástico, a ver a pintores simbolistas y en especial a los artistas de la Sociedad Nacional. Luis Vargas Rosas se va a Europa en 1919 y desea ir a París: "porque siento gran admiración por la pintura francesa moderna. Aman Jean, Puvis de Chavannes, Besnard, Cottet, son para mí grandes maestros" (Vyvyan 27), afirmación que evidencia el impacto que tienen en los alumnos de la academia las ideas difundidas, entre otros, por Backhaus.

Un año más tarde llega a París Henriette Petit. Ella se desanima ante la diversidad de tendencias y su reacción inicial es aferrarse a la formación recibida en su país: "Como profesores y alumnos no he visto todavía [nada] mejor que en Chile. Veo que estamos más adelantados de lo que creemos allá... Tenemos nociones y estamos al corriente de todo" (Díaz, 
Bohemios 162). Ella confirma sus postulados y visita el Luxemburgo para ver las obras de pintores conocidos: Aman Jean, Lucien Simon y Eugène Carrière. Camilo Mori, en tanto, va a París en 1920 y no tiene dudas: anhela ir a "ver a Aman Jean en el original" (Emar, Notas 59).

La homogeneidad de la formación chilena en el caso de estos jóvenes pronto se desarticula y en Europa los artistas se quedan sin sus referentes. “Aman Jean se desteñía, René Menard se ponía chocolate, Zuloaga se acartonaba" afirma Mori. El problema es que tampoco pueden comprender de inmediato a las nuevas corrientes debido a que ignoran un segmento de la historia artística que hace explicable y coherente la producción contemporánea. Petit señala en 1920: "no puedo admirar a los que aquí tienen como Dioses. Los futuristas, cubistas hasta dadaístas son los que descuellan. Es horroroso" (Díaz, Bohemios 170). Luego del duelo por la pérdida y el desprendimiento de sus certezas, la resolución de las fracturas implica iniciar una sostenida reflexión para entender las raíces y las expresiones de la nueva pintura y elaborar nuevos esquemas perceptivos y valorativos que permitan comprender la nueva pintura y sus raíces. El proceso puede tomar algunos años, ya que no se trata de caer en la imitación ni en el pastiche de las propuestas y los nuevos procedimientos constructivos; se trata más bien de encontrar un lenguaje plástico que los interprete.

París es oportunidad de crecimiento y renovación y a veces amenaza que destruye las convicciones: para todos es una experiencia de ambigüedad y angustia, de crisis por cuanto tienen la vivencia de algo que se rompe. Algunos creadores dejan de pintar por un tiempo y otros para siempre como Abelardo Bustamante, quien regresa a Chile "amargado ... se convenció que no era pintor -quebró la paleta y regaló su caja de pintura- No entendió nada" (Díaz, Bohemios 362); otros hacen copias en los museos, asisten a las academias libres y discuten en los cafés; visitan salones y museos, estudian y leen en diarios, revistas y libros sobre "los modernos"; viajan al campo en busca de nuevos paisajes, a la Bretaña para retratar mundos alejados de la modernidad, a otros países para asentar sus convicciones, tomar clases o conocer nuevas tendencias. Todos confrontan sus saberes, dibujan, quedan disconformes, dudan de sus talentos, pero tienen una convicción: "No volveré a Chile en Aman Jean” (Díaz, Bohemios 233) dice el mismo Vargas Rosas en 1922.

Los pintores como Vargas Rosas, Petit y Mori entienden que la capital francesa se constituye para ellos como una nueva escuela donde coexisten 
varias tendencias, pueden ver directamente, sin mediaciones, la evolución artística, llenar sus vacíos, descubrir su sensibilidad y sus necesidades en un campo artístico. Ellos se abren a la "tradición de la ruptura", trabajan para renovar sus paradigmas y modifican sus creencias. La lenta familiaridad con las obras, el diálogo con otros artistas, el diseño y el carácter pedagógico de las muestras resultan centrales en este aprendizaje.

Vargas Rosas confiesa la relevancia de los diálogos parisinos con Juan Emar para su nueva comprensión del arte: "mi criterio de antes se ha transformado" (Díaz, Bohemios 185). En enero de 1922 le cuenta a Petit: "ya me gusta Cézanne... es el punto de partida hoy día -en mis orientaciones de arte-" (Díaz, Bohemios 218). En cuanto a las exposiciones, el caso ejemplar es "Cien años de pintura francesa", organizada en 1922 por André Lhote y Jacques Emile Blanche, con catálogo escrito por el primero. Vargas Rosas comenta la muestra en carta a Petit en marzo del mismo año:

Se escogieron solamente aquellas personalidades que marcan el camino desde Ingres al cubismo... Nunca mejor puede uno darse cuenta de la parábola que ha descrito la pintura -desde hace un siglo- y porque en la época que corresponde Ingres está tan bien -como ahora Picasso- y por esto no hay que asustarse. (Díaz, Bohemios 228-229)

Un juicio semejante tiene Wanda Morla, quien destaca en marzo de 1922 el carácter pedagógico del montaje, pues da la posibilidad de entender la nueva pintura y renovar las ideas plásticas.

Me dejó convencida que el espíritu que no es porfiado puede entrar fácilmente en la comprensión modernista. Prueba de ello el horror que me produjo el retrato de Renan hecho por Bonnat y otras obras de academia demasiado hechas y de una realidad sin interés, prueba de ello también el gusto que sentí frente a un Cézanne, a un Matisse, a un Manet y otros aun más avanzados. (Díaz, Pájaro 104)

\section{Sara Camino en París: artistas y manifiesto}

El matrimonio Backhaus-Malvar llega a la capital francesa en junio de 1921. Ellos se instalan en Bellevue (sur Seine et Oise), alejados de la capital en una suerte de reclusión y existencia muy austera. No tienen una vida 
de café, bulevares, academias libres como la mayoría de los pintores de la época, pero visitan París en un tren de cercanías que llega a la Gare Montparnasse. Ellos desean permanecer un breve tiempo en Francia y luego trasladarse a Florencia, ciudad que posee una tradición artística más cercana a las creencias e intereses de Backhaus.

Aunque viven en los alrededores de París, la ciudad para Sara es un lugar lleno de posibilidades y una oportunidad de crecimiento. Su búsqueda, a diferencia de Backhaus, está ligada a las propuestas emergentes. Sara, en España, desarrolla una pintura que más bien adhiere a las opciones de Backhaus y posee una voz contenida, en proceso. En Francia, ella pareciera "llevar una vida secreta a mayor profundidad" y sus propias inquietudes no las presenta en forma abierta. Así al menos lo percibe su amiga Wanda Morla en marzo de 1921: "Es una niña muy buena que esconde su talento por bondad, y lo comprendo, teniendo su marido que la admira, eso le basta, y no tiene otra ambición que la de pintar para su gusto" (Díaz, Pájaro 86).

La propia Wanda, sin embargo, en junio de 1922 advierte que Sara genera espacios para la nueva sensibilidad, pues sostiene que hay cuadros modernos en los muros de la casa de Bellevue: ellos tienen "muchos muebles antiguos... cuadros de todos estilos desde el más puro estilo pastoril o bíblico (Puvis Chavanesco con alma) hasta los de osados coloridos modernos (últimas producciones de los artistas)" (Díaz, Pájaro 197). No hay invisibilidad ni negación, pero sí subordinación²

En términos aparienciales, pareciera que Sara cumple los deseos del otro, que su posición dentro de la pareja es la de una discípula que imita a su maestro, mentor y marido y que, en consecuencia, hace un arte que se rige por un gusto ajeno. Pero ella se interesa por la nueva visualidad y en París comienzan a emerger sus preferencias, de modo que más bien advertimos en aquella postura un disfraz que enmascara la "treta del débil", un artificio para desarmar la figura de autoridad y defender su proyecto individual. Ella sabe de sus potencialidades personales, él también las aprecia, pero Sara las "esconde", se disminuye frente al otro, y si bien no puede "decir que no sabe", prefiere "no decir que sabe"3.

El entrelazamiento complejo e intrincado en la vida de las parejas artistas genera en este caso una dialéctica de negación y afirmación, de

Ver: Cortés, Gloria. Modernas, Historias de mujeres en el arte chileno, 1900-1950. Santiago, Origo, 2013.

Ver: Valdés, Adriana. Composición de lugar. Santiago, Universitaria, 1995. 
borrarse y emerger. En forma progresiva, Malvar abandona su postura subalterna, comienza a nivelar su vínculo asimétrico con Backhaus y a desanudar los condicionamientos que la atan. Ella elabora una imagen menos alienada y menos dependiente de la mirada del otro y abre un espacio para construir un lugar para su voz. Ella "era toda vida, vehemencia y empuje”, recuerda Wanda (Díaz, Pájaro 339).

Backhaus comprende que, para su mujer, la estadía en Paris es una gran oportunidad de desarrollo; asume que ella entiende bien el arte nuevo de modo que él pasa a ocupar un lugar más subordinado dentro del matrimonio y a colaborar en el crecimiento artístico de su mujer (339). Wanda Morla, en abril de 1922, sostiene que él "ha comprendido que su mujercita promete más y le cede el sitio de honor, y más aún, le prepara las telas, las pinturas y la mira trabajar, con ternura" (Díaz, Pájaro 129). Se articula una relación nueva al interior de la pareja y se redefinen los roles y los estereotipos establecidos en la sociedad patriarcal. ${ }^{4}$

Sara valora las tendencias, transformaciones e interrelaciones del 'espíritu nuevo' e inicia en la capital francesa una práctica que comienza a visibilizar su renovación plástica. Su cambio se funda en una educación no institucionalizada, conocimiento que surge a través de múltiples instancias. El estudio y la lectura acerca de los 'modernos' en diarios, revistas y libros, la lenta familiaridad con las obras a través de la ida a museos y galerías, las visitas a muestras individuales y colectivas que explicitan 'la razón de ser' de la pintura moderna -como la organizada por Lothe y Blanche- son esenciales para confrontar y ampliar sus paradigmas plásticos.

El diálogo con artistas, críticos y conocedores del arte nuevo, la formación de redes que permite acceso a artistas muy destacados, es otro modo de aprendizaje. La pareja Backhaus-Camino visita a Eugenia Huici, muy amiga de la familia Morla Lynch, y a través de ella frecuenta a varios actores centrales de la vanguardia ${ }^{5}$. Eugenia es una mujer de singular originalidad y discernimiento. Como sostiene Richardson (web), "Besides being one of Picasso's most perceptive patrons-the owner of some of his

\footnotetext{
Ver: Chadwick, Whitney e Isabelle de Courtivron Eds. Los otros importantes. Creatividad y relaciones intimas. Madrid, Cátedra, 1994.

5 Ella es conocida también como Madame Errázuriz, pues estuvo casada con el pintor chileno José Errázuriz, y es muy cercana a Luisa Lynch, madre de la joven Wanda Morla. Sara Malvar confiesa que en París en casa de Eugenia Huici vio la colección de Soirées de París, "hoy día difícilísima de reunir". Agrega que allí también encontró Meditations esthétiques que "leí por primera vez en París en el ejemplar dedicado por el propio Apollinaire a Madame Errázuriz es uno de los libros más importantes a mi entender, y más luminosos que se hayan escrito sobre cosas de pintura." (Emar, Notas 186)
} 
greatest, late-Cubist paintings-she managed to exert, in her subtle way, a more radically modernizing influence on mid-twentieth-century taste than most of those who were indebted to her realized" ${ }^{6}$. Ella posee un vasto conocimiento del mundo artístico europeo que le permite apreciar, en forma prematura, "opciones estéticas ... que estaban muy lejos de obtener el consenso y la consagración" como señala Canseco Jeréz (ctd. en Ortiz 2). Por ello, Stravinsky afirma que Eugenia posee "una comprensión sin igual respecto a un arte que no era el de su generación” (ctd. en Ortiz 2).

Mujer de gran belleza, retratada por varios pintores en Londres y París, Huici se convierte en mecenas y amiga cercana de creadores como Pablo Picasso -ella le presenta al marchand y galerista Paul Rosenberg-, Blaise Cendrars, Le Corbusier, Igor Stravinsky, Robert y Sonia Delaunay, Mateo Hernández, Arthur Rubinstein y Sergei Diaguilev -ella convoca a quienes participan en el ballet Parade-. Partidaria del minimalismo, su aporte esencial, a juicio de críticos y artistas, estuvo en la decoración de interiores.

Por otra parte, el vínculo con Vicente Huidobro también es para Sara María muy estimulante. El poeta llega a París en 1917 y, en su departamento, en los cafés de Montparnasse, en las revistas en que colabora y en las que funda, en las polémicas en que participa, en los libros publicados y en los proyectos que realiza, se encuentran, entre muchos otros, artistas como Pablo Picasso, Juan Gris, Guillaume Apollinaire, Pierre Reverdy, Blaise Cendrars, Paul Dermée, Jacques Lipchitz, Hans Arp, Robert y Sonia Delaunay, Le Corbusier, junto a críticos como Maurice Raynal, André Salmon y Waldemar George. Wanda Morla advierte la relevancia de estos artistas y de las redes establecidas a través de Eugenia Huici y Vicente Huidobro: "Los Backhaus ... están relacionados con los mejores pintores y artistas de ahora" (Díaz, Pájaro 222).

Las redes que le ofrecen Huici y Huidobro le brindan a la pareja chilena amistad y cercanía, espacios alternativos más flexibles, diálogo abierto, cosmopolita y vinculado a otras artes.

Las nuevas creencias, Sara las hace visibles al fotografiarse rodeada de emblemas del arte nuevo. El retrato, que data de comienzos de los años veinte, muestra a una mujer elegante y moderna, de aire andrógino, ojos enormes, largos dedos y mirada penetrante, pelo corto al estilo garçonne y lazo de artista al cuello. Ella se integra a esta figura

Richardson, John en http://catdir.loc.gov/catdir/samples/random044/2001031623.html 
ambigua "caracterizada por una estética rebelde de poses provocadoras e indumentaria masculina. Un nuevo modelo de mujer que desafía a la sociedad de su tiempo haciendo público su criterio y adoptando actitudes al margen de cualquier estereotipo femenino"(Cendán 409), postura que ya se advierte en la manera en que redefine su relación con Backhaus.

A la vez, y en una afirmación radical de su abandono de la enseñanza académica y del gusto occidental, aparece flanqueada por dos estatuillas de origen pascuense. El moai que está a su izquierda y que sostiene con sus dos manos es una escultura de madera tallada que representa un espíritu guardián o 'aku aku', figura descarnada a la cual se le ven los huesos de las costillas y cuya función es espantar los malos espíritus. La estatuilla a su derecha corresponde a un 'moai tangata', representación en madera de la figura masculina de cabeza alargada y estómago prominente, la cual recuerda ancestros y espíritus de antepasados?

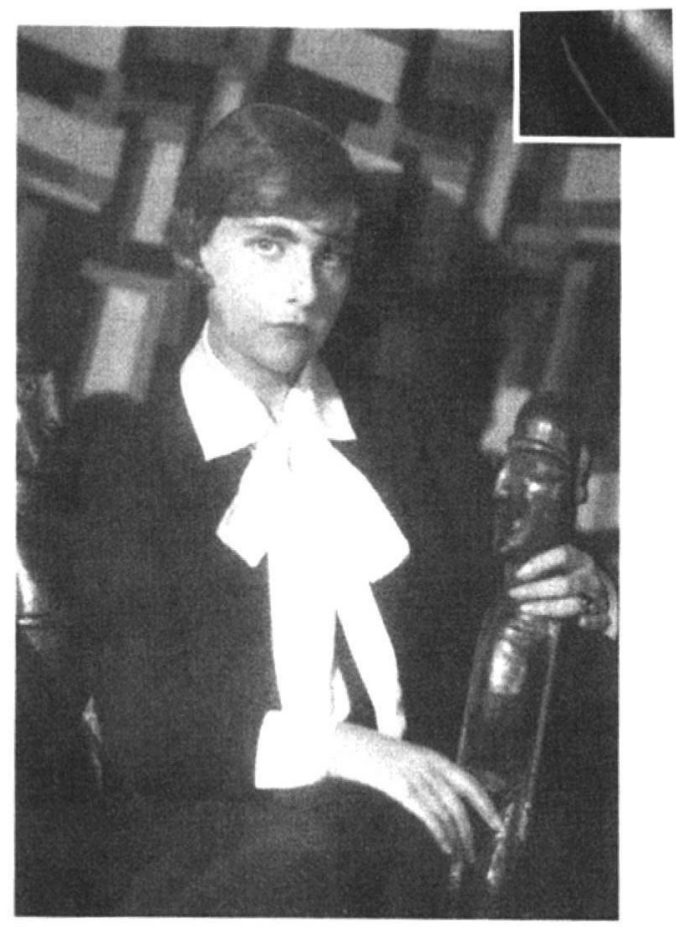

Figura 1. Retrato de Sara Malvar a comienzos de los años veinte, rodeada de emblemas del arte nuevo.

La fotografía de Sara Malvar está tomada del libro de Pilar Subercaseaux, Las Morla: huellas sobre la arena. Santiago, Aguilar, 1999. 
El interés de la pintora chilena por las culturas y civilizaciones antiguas se encuentra en consonancia con la apertura del arte moderno al primitivismo negro, con su apropiación estética basada en elementos africanos y polinésicos, influencia muy beneficiosa, entre otras, para cubistas y surrealistas.

La preferencia vanguardista se revela, además, en el gran tapiz que observamos detrás de Malvar. Carente de toda figuratividad y construido con una singular disposición de formas geométricas de color, rectángulos horizontales y verticales de distintos tamaños y colores. El tapiz se conecta con las avanzadas tendencias del arte moderno, el arte abstracto y, en particular, con los “objetos simultáneos" elaborados por Sonia Delaunay ${ }^{8}$.

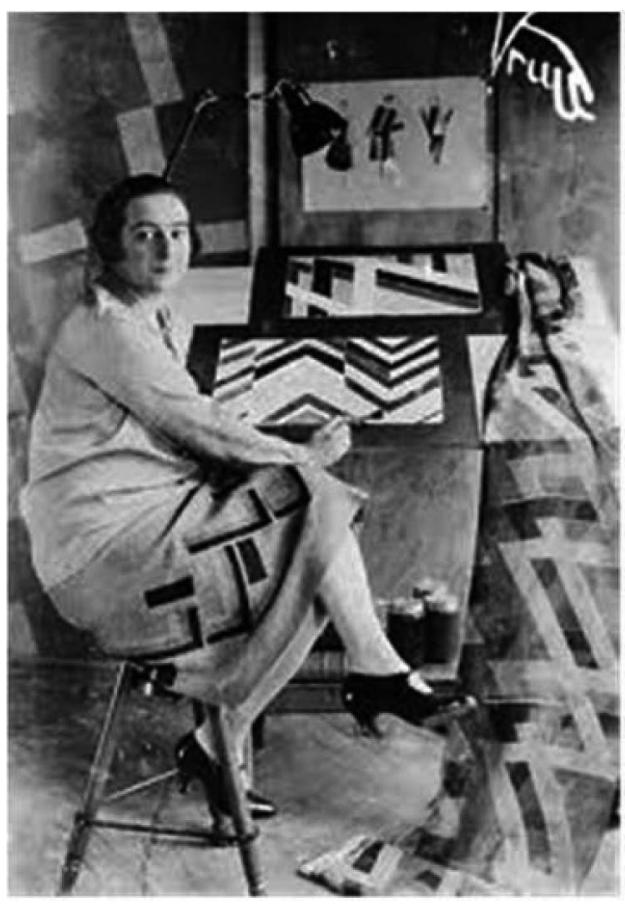

Figura 2. Sonia Delaunay en su taller de textiles del boulevard Malesherbes, Paris hacia 1925. Foto de Germaine Krull.

Entre los objetos está el cobertor para la cama de su hijo, pantallas de lámparas, una caja de juguetes, almohadas, encuadernaciones y tapas de libros en forma de collages, diseño de ropa y, además, trabajos textiles, bordados, tapices y alfombras. Ver los textos de Dutching, Ruiz del Árbol y Godefroy en obras citadas. Las fotografías de Sonia Delaunay están en el libro de Cécile Godefroy. Ver Referencias bibliográficas. 


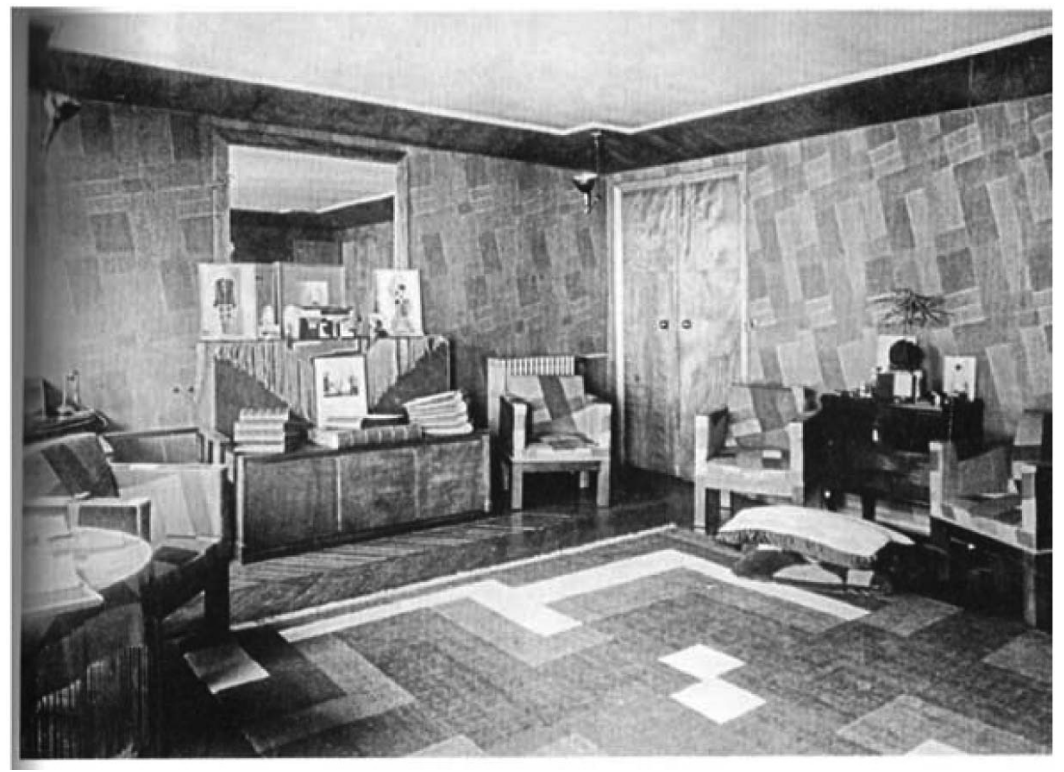

Figura 3. Salón del Boulevard Malesherbes diseñado por Sonia Delaunay, hacia 1925. Foto de Joaillier Fréres.

Esta artista desde la década de 1910 expande su trabajo visual y la práctica simultánea más allá del lienzo, "rompe la frontera entre las bellas artes y las artes aplicadas" y adorna "con colores una gran diversidad de soportes con distintas técnicas" (Godefroy, "Sobre los orígenes...” 26). Sonia se identifica con los artistas, "incluidos dadaístas y futuristas, que querían demoler la hegemonía de la pintura de caballete para sacar el arte del estudio y llevarlo a las calles" (Chadwick 48).

Malvar, al aparecer junto al trabajo de Sonia Delaunay en una fotografía que bien pudo ser tomada en el departamento de Sonia, exhibe su interés y su entendimiento acerca de la expansión del 'arte de caballete', la convergencia del arte y de la artesanía que se proyecta en los objetos de la vida cotidiana y la aceptación de las creaciones 'utilitarias' con cualidades estéticas y plásticas al nivel de cualquier obra de arte.

La fotografía es una toma de posición y una suerte de manifiesto, pues Sara María explicita sus nuevas certezas, así como sus rechazos. Define un "nosotros" -quienes adhieren a la modernidad visible en estatuillas, formas geométricas y tapiz- y un "ellos" -lo negado y ausente en el retrato: arte nacionalista, académico y figurativo-. Asimismo, la foto, al estar inscrita en el cruce entre lo antiguo y lo moderno, lo polinésico y lo 
europeo, lo periférico y lo central, da cuenta de una doble relación del intelectual latinoamericano con la modernidad europea.

Malvar asume un lugar de enunciación que es híbrido porque se sitúa en una encrucijada de culturas, en un espacio atravesado por influjos opuestos y complementarios, y en un cruce temporal porque aun cuando valora la tradición, es capaz de asumir nuevas tendencias. Desde estas confluencias, por una parte, acoge el legado universal, lo que llega de lejos y surge en otro lado -el tapiz-; por otra, devuelve algo desde la periferia las estatuillas pascuenses- y así disloca el origen al mostrar, ampliándolo, la falta que hay en todo universalismo, la "materia negada que lo hace, a la vez, menos universal ... y devela nuevas potencialidades" (Aguilar 12). Ella comparte "la pasión de los jóvenes pintores que encontraron en el Arte Negro (africano y polinesio) una nueva corriente vivificante" (Emar, Notas 186).

El doble gesto anterior convierte a la fotografía en la manifestación de cómo se construye Malvar como sujeto cosmopolita: no posee "una identidad fija y definida, sino que es una instancia móvil, operativa y disponible que se propone ... redefinir las nociones de lo local, lo nacional y lo universal" (Aguilar 11).

\section{Sara Camino: copias, poemas pintados y trabajos visuales}

Las renovadas convicciones de Sara Camino se amplían a través de un conjunto de prácticas artísticas. La academia de Bellas Artes, entre sus métodos pedagógicos, considera necesario el trabajo de copiar las obras esenciales de la pintura. Al copiar, se busca "reproducir o imitar de manera idéntica una obra, cuestión que implica comprender profundamente al original, tanto en su contenido iconográfico como en sus técnicas y procedimientos" (Honorato y Gallardo 14).

Los artistas chilenos que van a Europa, entre la segunda mitad del siglo XIX y el inicio del XX, realizan copias en los museos como parte de su trabajo como pensionado, y varias de sus telas luego conforman la colección del Museo de Bellas Artes. Sara transgrede esta enseñanza plástica y se independiza de los gustos de Backhaus, pues ella 'copia' no a los pintores de la tradición venerados por la academia -en particular "el arte neoclásico y la temática histórica que, a su vez, incluía imágenes de contenido religioso y mitológico" (Honorato y Gallardo 25)-, sino a 
los creadores del arte contemporáneo. La artista chilena utiliza como modelos algunas témperas cubistas de Picasso, telas de André Dunoyer de Segonzac, Auguste Renoir y Raoul Dufy.

El trabajo encargado por Vicente Huidobro a Sara, en 1922, es otra evidencia de los nuevos intereses de la joven chilena. El poeta escribe diversos caligramas en que la figura visual es construida o dibujada por las palabras, y con ellos elabora los poemas pintados, textos con los que organiza la exposición Salle XIV abierta el 16 de mayo de 1922 en el Théâtre Edouard VII de París y clausurada apenas tres días después por las protestas del público.

Los poemas pintados son parte de una "tradición occidental que se inicia con los griegos clásicos" y en el experimento huidobriano es la presencia del color "lo que lo singulariza dentro de las variadas y radicales expresiones vanguardistas” (Sarabia 59). Entre estas, la creación de Sonia Delaunay junto a los poetas de la vanguardia, labor que pone en relación la poesía y la pintura a través de distintas modalidades, resulta esencial para concebir los poemas pintados de Huidobro ${ }^{9}$.

La artista en París trabaja los contrastes de color en poemas y libros como "Pascua en Nueva York" de Blaise Cendrars, "Alcoholes" de Guillaume Apollinaire y Los trasplantados de Ricciotto Canudo. En 1913 el color y el movimiento dialogan con los versos libres de La Prosa del Transiberiano y de la pequeña Jehanne de Francia de Cendrars, propuesta considerada "una de las obras maestras de la vanguardia literaria y pictórica ... y en la que por primera vez se funden poesía y pintura” 10 . Sonia confiesa que su anhelo fue "conseguir una armonía cromática que se desarrollaba en paralelo al poema”, pues la artista no ilustra la poesía, sino que la había "interpretado" no con "imágenes ni con objetos en el sentido tradicional, sino con colores, líneas, sensaciones, sentimientos. Inspiración pura" (Godefroy, "Sobre los orígenes de lo simultáneo" 33). El resultado es "un entrelazado de formas puras y coloreadas que evoca el avance del viajero en un tren” (33).

\footnotetext{
$9 \quad$ El simultaneísmo es un "neologismo extraído del tratado sobre el contraste simultáneo de los colores de Eugène Chevreul, que establece que las tensiones y las vibraciones ópticas que genera la relación entre los colores complementarios sugieren el movimiento conforme al modelo rítmico de la danza y la música. Los Delaunay asociaban el simultaneísmo a la vida moderna y al desarrollo urbano, y querían llevarlo a todos los ámbitos posibles". Ver: Ruiz del Árbol, Marta. http://artishockrevista. com/2017/07/04/sonia-delaunay-arte-diseno-moda/

10 Ver Ruiz del Árbol, Marta. http://artishockrevista.com/2017/07/04/sonia-delaunay-arte-diseno-moda/
} 
La experimentación entre pintura y poesía la profundiza en la década de los veinte en París, pues pinta y hace bocetos con los poemas de amigos como Nicolas Beauduin, Vladimir Maiakovski, Joseph Delteil, Philippe Soupault, Iliazd -abreviatura de Illia Zdanevich- Guillermo de Torre y Ramón Gómez de la Serna, textos que luego cuelga en las paredes de su departamento" ${ }^{11}$ Ella, como se observa en el boceto de "Abanico de palabras", hecho con tinta china y lápiz sobre papel, otorga movimiento y dinamismo, reordena y condensa, elimina ornamentos, juega con la tipografía y logra nuevas armonías ${ }^{12}$.

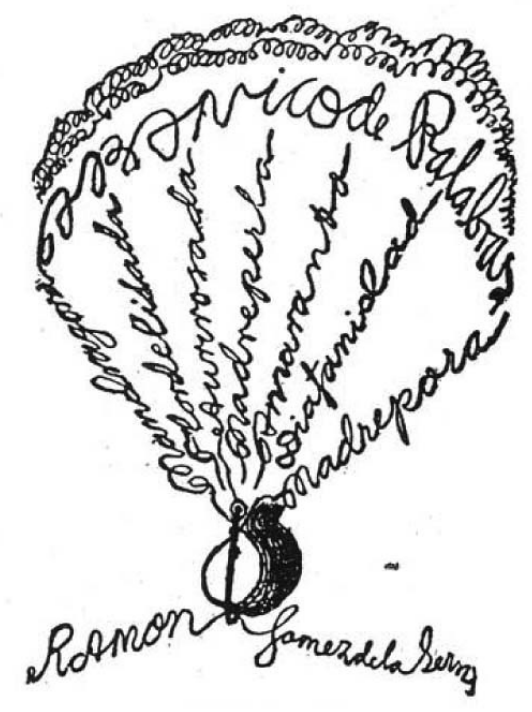

Figura 4. "Abanico de palabras" que el autor regaló a Sonia Delaunay.

\footnotetext{
11 René Crevel confiesa que "los muros estaban cubiertos de poemas multicolores" (Godefroy, $S a$ Mode 45)

12 Ver Ismos de Ramón Gómez de la Serna. Buenos Aires, Poseidón, 1943. La imagen del “Abanico...” hecho por Delaunay está en el libro de Marta Ruiz del Árbol. Ver Referencias bibliográficas.
} 


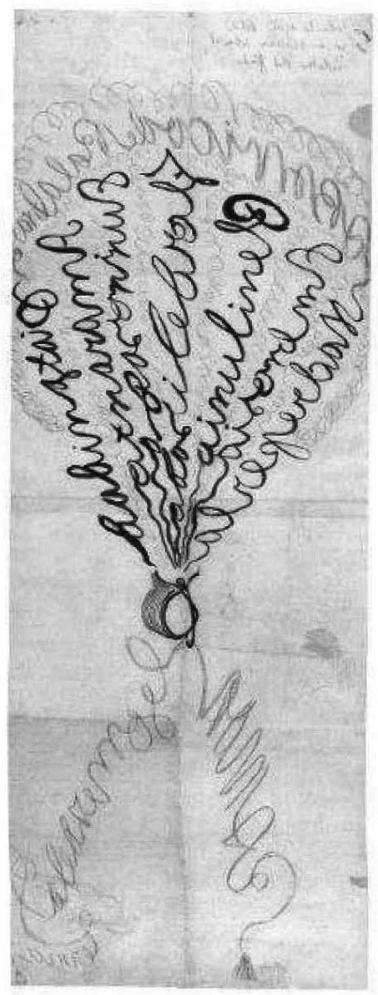

Figura 5. Boceto del abanico-poema. Ilustración de un poema de Ramón Gómez de la Serna, 1922.

La otra invención de Sonia es la 'cortina poema'. Colgada a la entrada del departamento en el $n^{\circ} 5$ del boulevard Malesherbes, o utilizada por las mujeres como una capa, "la cortina -poema es bordada con hilo de lana roja y negra -una asociación inédita que subraya la raíz latina común de "textile" (textilis) y "texto" (textus)" (Godefroy, Sa mode 45-46).

Los robes-poemes hechos al comienzo con textos de Tristan Tzara y Blaise Cendrars son otro aporte de Sonia. Luego, utiliza versos de "Joseph Delteil, Philippe Soupault, Vicente Huidobro y otros” (Duchting 55) ${ }^{13}$. Fascinada por la imbricación natural que "hace Tzara de la palabra y la imagen, ella imprime o borda muchos de sus poemas por medio de cintas sobre la tela", objetos híbridos que permiten a la artista "explorar las

\footnotetext{
13 En julio de 1922 colabora con Sonia Delaunay en la creación del "poema-vestido" (Ver René de Costa, "Salle XIV: un proyecto a largo plazo". Vicente Huidobro. Obra Poética. Coordinador Cedomil Goic. Madrid-Santiago, Allca XX, 2003, pp. 1683).
} 
propiedades plásticas de la palabra sobre la ropa y al poeta experimentar la tela como un nuevo soporte de la investigación poética" (Godefroy, Sa Mode 46). Sonia estampa los versos con variados colores y lanas en tejidos y vestidos y también hace acuarelas que muestran los vestidos-poemas ${ }^{14}$.
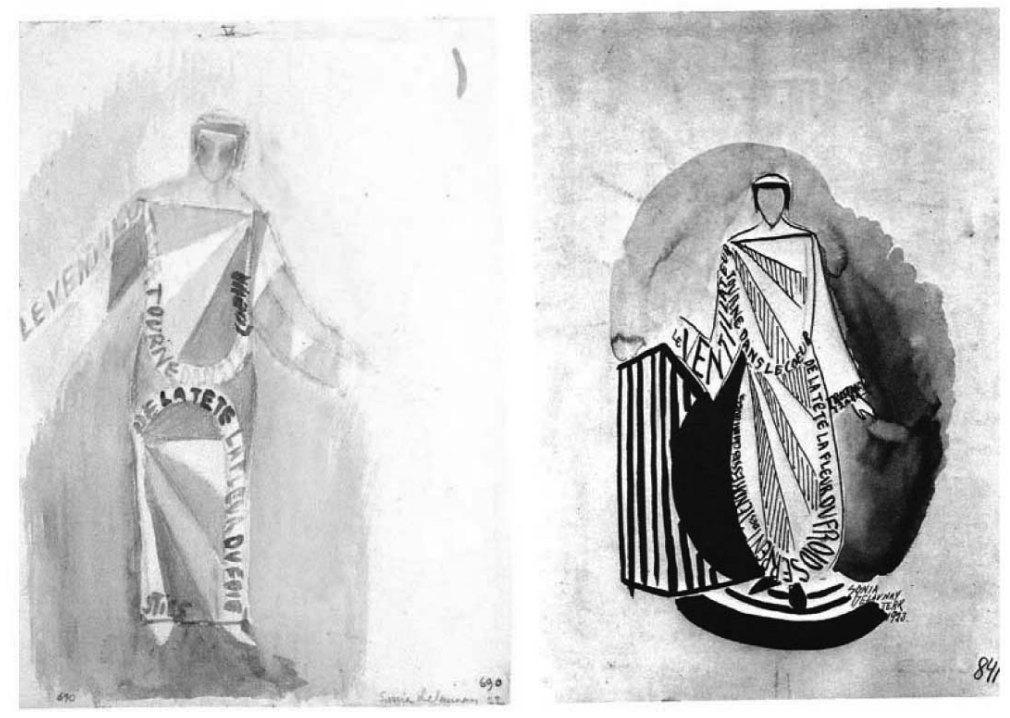

Figura 6. Vestidos-poemas, con textos de Tristan Tzara. Izquierda acuarela. Derecha tinta china. 1923. Fotografía de Guillermo de Osma.

Los poemas pintados de Huidobro se insertan en este espacio de experimentación e hibridez. Sonia hace robes-poemes y rideau-poème, estampa y dibuja versos en la ropa y en la tela; Huidobro parte de esta propuesta, pero la modifica, pues hace poemas pintados: los escribe y luego "dibuja/estampa" colores en ellos; así, gesta otra novedad, la plástica. El resultado es un texto literario-visual en que todo converge y diverge, fusión de significantes, pero cuidando de no confundirlos de modo tal que ambos siguen abiertos. El sentido cambia, se refracta y se multiplica.

En el robe-poeme de Cendrars, "Sobre el vestido lleva un cuerpo", que completa Delaunay, el eje "está representado por una dinámica compleja y renovada entre el vestido y el cuerpo, entre la decoración y la anatomía, entre la estabilidad y el movimiento" (Cortiana web) ${ }^{15}$. En los poemas pintados, existe una relación entre la letra y la imagen, la

\footnotetext{
14 Los vestidos-poemas se encuentran en el libro de Marta Ruiz del Árbol. Ver obras citadas.

15 Ver «Sur la robe elle a un corps». Poème-manifeste de Blaise Cendrars. Rino Cortiana http://books. openedition.org/pupo/2529?lang=fr
} 
sucesión y la simultaneidad, el ver y el leer y, como puntualiza Sarabia al seguir a Foucault, entre "mostrar y nombrar, figurar y decir, reproducir y articular, imitar y significar, mirar y leer" (Sarabia 1434) ${ }^{16}$.

Los textos huidobrianos se basan en íconos urbanos -Torre Eiffel-, íconos rurales -"Moulin"-, objetos cotidianos -Piano-, y naturaleza -“Ocean", "Marine", "Paysage"-, que se construyen con un lenguaje hecho de asociaciones nuevas y discontinuas que requieren de un lector/ espectador activo que rearticule los fragmentos.

El poeta, después de la muestra Salle XIV, le pide a Sara Camino "nuevas versiones de los poemas pintados desaparecidos para poder publicar" más adelante la edición de Salle XIV (Pérez 40). Así, ella realiza el boceto a color del caligrama "Moulin" (acuarela sobre papel) "utilizando el poema impreso, a una sola tinta, encartado en el catálogo de la exposición", y hace un boceto coloreado del caligrama Paysage, sobre el poema reproducido en dicho catálogo (acuarela sobre papel) (Pérez 35).

El molino del poema huidobriano coloreado por Malvar posee como eje un círculo rojo de donde nacen cuatro aspas, figuras geométricas contrapuestas y concéntricas. El giro permanente destacado por medio de un estribillo genera la molienda del tiempo -días, horas, meses y años, transcurrir cotidiano que se expande y establece el ritmo de la naturaleza y del hombre. El movimiento continuo da un carácter eterno al molino, figura que se alza como un demiurgo: otorga el bienestar y la desgracia, decide y regulariza el ciclo de la vida y de la muerte.

\footnotetext{
${ }_{16}$ Huidobro conoce a Sonia y Robert Delaunay en España en 1918. El poema "Tour Eiffel" del mismo año está dedicado a Robert Delaunay y en la portadilla de la edición príncipe, se reproduce la pintura La Tour, (1910-Paris) de este artista. Ver Vicente Huidobro. Obra Poética. Coordinador Cedomil Goic. Madrid-Santiago, Allca XX, 2003.
} 


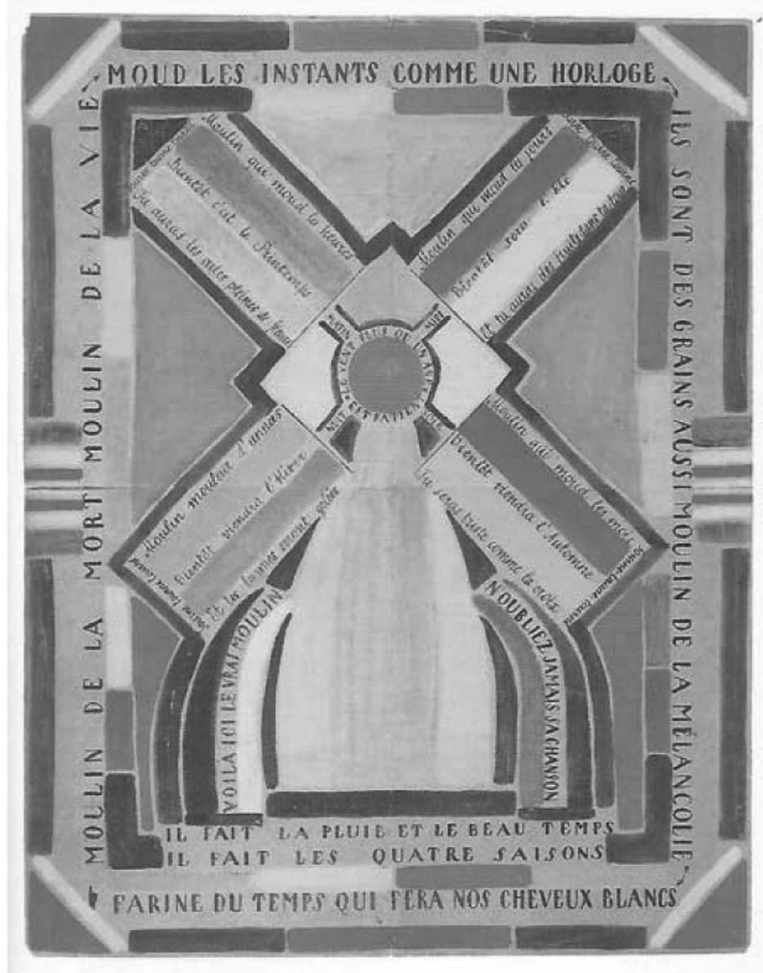

Figura 7. Poema "Moulin" de Vicente Huidobro pintado por Sara Malvar.

El giro, la expansión y el dinamismo se articulan en términos plásticos a través del color, y en este sentido, la obra de Robert Delaunay es esencial para Malvar. Si la piedra del molino es un círculo -sol, luna- y una rueda del universo, también es un disco. Robert Delaunay asume la forma circular "como el modelo más plástico y más fiel a la realidad de la energía cromática”(Dutching 41). El disco es "para él una 'forme mobile totale' que representaba tanto la totalidad y simultaneidad de los colores, como el movimiento universal y la expansión de la energía luminosa creada por los colores", ideas que se concretan en su pintura llamada "Disco simultáneo" (1912-1913).

Malvar trabaja estas propuestas en el molino. Ella utiliza colores contrapuestos entre sí, tonos rojos y azules enfrentados en el centro y en el marco interior; alrededor aparecen otros contrastes de colores que se enfrentan unos a otros, simultáneamente y en relación con la totalidad. La explosión y potencialidad expresiva del color, la simetría de equilibrios contrarios en el marco exterior, la ruptura de la simetría en el interior, 
la prioridad y el esquema geométrico, los "arcoíris fragmentados" aparecen en el boceto de Sara María ${ }^{17}$. El molino es energía vital, totalidad y movimiento que surge de la relación de medidas desiguales y de los contrastes.

En "Paysage", el "primer caligrama de vanguardia de Huidobro" (Goic 18), perteneciente a Horizonte cuadrado (1917), el poeta elabora un hecho nuevo e inhabitual que sorprende y extraña. Definido como una construcción histórica producto de un modo de mirar, el paisaje es el lugar desde el cual el sujeto se localiza, se identifica y construye su yo nacional (Schoenennbeck, "Muerte" 256). La mirada describe el espacio real recreándolo y volviéndolo paisaje, de modo que "no solo represento un referente previamente existente, sino que también lo produzco". Así, el paisaje tiene un carácter performático porque "es capaz de referirse a algo y, a la vez, [realizar] la descripción de ese mismo algo" (Schoennenbeck, “Paisaje..." 92).

En la pintura chilena existe una "usual identificación del paisaje como la representación de espacios naturales (la cordillera, el campo, la campiña, el mar)"(Subercaseaux 6), procedimiento que permite una identificación nacional a través de la mediación invisibilizada de las artes. En la literatura ocurre algo semejante, pues Mariano Latorre sostiene que esta "debe alimentarse con los fondos de nuestra raza y nuestro paisaje". El único gran tema y motivo de la literatura chilena es, para Latorre, Chile. "La literatura que no habla sobre su paisaje y sus caracteres, no existe". . El espacio natural es admirable pues se le otorga un carácter artístico que deviene alma de la nación.

"Paysage" está escrito en la lengua y en la ciudad de la vanguardia, París. Huidobro se localiza en un campo cultural cosmopolita y conoce los nuevos discursos para entender y hacer arte; él no se nutre del espacio chileno, sino de la escuela de París, -donde participan los Delaunay y Picasso, este último, a quien le dedica el poema- y del espíritu nuevo encarnado en Apollinaire -el caligrama-.

Ver: Read, Herbert. A Concise History of Modern Painting. New York, Preager, 1968. 


\section{PAISAJE $E^{a}$}

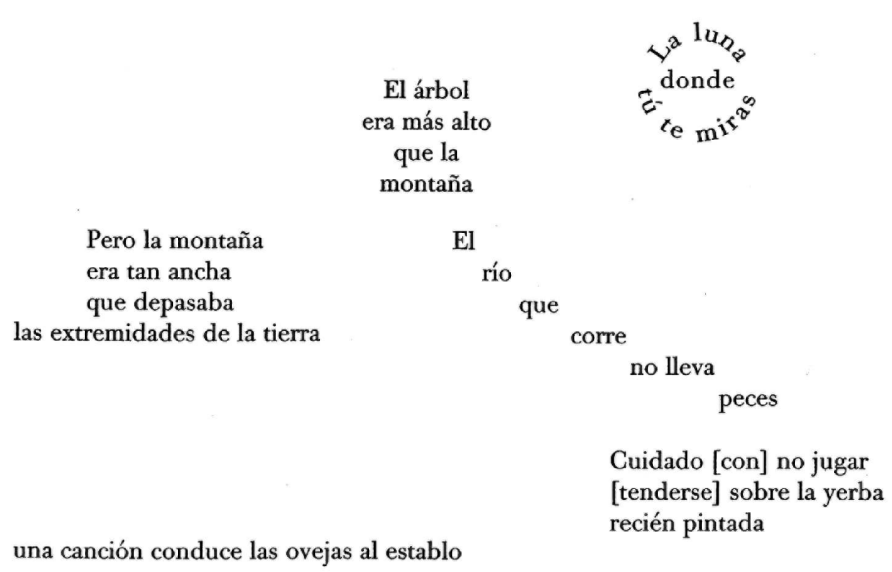

Figura 8. "Paisaje”, caligrama de Vicente Huidobro.

El escritor chileno, como lo afirmara en el Non Serviam (1914), cuestiona la realidad conocida al proponer insólitas manifestaciones de la naturaleza. Estas desarticulan los marcos de referencia para una normal orientación en el mundo, ofrecen una nueva imagen de la realidad y desautomatizan las percepciones. El poeta rompe con la representación del paisaje clásico -espacio ideal donde el árbol, la montaña y el agua están muy bien organizados y el hombre vive en armonía con la naturaleza- y del paisaje nacional a través de una cita paródica de este, que disocia el vínculo entre la nación y el paisaje. Huidobro construye uno creado con un nuevo código de producción que desterritorializa el paisaje.

El caligrama no se puede interpretar de acuerdo a una estética representacional porque posee un sentido inédito, transgrede categorías, amplía e inaugura otros mundos, tiene sus propias leyes, su propia verosimilitud y requiere de un lector activo. El universo creado pasa de la descripción y la figuración habitual del paisaje chileno a la abstracción y a la síntesis; de lo pintoresco a lo pictórico; de la imitación al desciframiento de una forma; del modelo a la parodia del modelo.

La lectura del poema propone un recorrido textual, temporal y sucesivo, y otro visual, espacial y simultáneo, acorde con el género 
pictórico del título del poema. El soporte lingüístico se distribuye de modo singular en la página en blanco; los versos adoptan diversas posiciones, pues se alinean de manera usual para diseñar el jardín, en forma escalonada para figurar el río, o, de modo circular, para construir la luna; los versos son breves, se descomponen, fragmentan y carecen de puntuación.

La orientación de la lectura es novedosa, pues el ojo cruza la página de manera diagonal de derecha a izquierda -luna, árbol, montaña- y continúa a mitad de página con un descenso escalonado que cambia la diagonal porque baja de izquierda a derecha -el río-. Al mismo tiempo es tradicional, ya que los versos inferiores relativos al jardín están ordenados en una estrofa. Huidobro acude a "todas las libertades textuales -de asociación, de dirección, de extensión, de disposición, de referencia" (Yurkievich 53).

Malvar, al igual que Huidobro, se localiza y se nutre de los discursos artísticos emergentes en París. Su boceto profundiza el quiebre del texto poético con la representación de carácter realista y con el paisaje nacional, pues su mirada no está mediada por "los anteojos pintorescos" como dirá ella más tarde. Sara confirma las propiedades de los componentes del paisaje, sitúa a algunos en posiciones nuevas -el establo se sale del límite, queda "fuera de lugar" - y utiliza colores de modo variado. Algunos son semejantes a los de la naturaleza -verde para el pasto, tonos de verde en las hojas del árbol, azul para el río-; otros no la imitan -amarillo solar para la luna, lila francés para la montaña y el cielo- o la transforman como la gradación del azul del río que se aclara y culmina casi transparente en las profundidades de la tierra.

Sara resignifica el caligrama porque si Huidobro desterritorializa el paisaje, ella lo reterritorializa al enraizarlo en el continente latinoamericano. Los elementos del referente nacional -la montaña y el río- los desrealiza, pues desbordan los límites vertical y horizontal y, los combina con el árbol que es un palo de agua o tronco del Brasil, brasilidad que se complementa con el azul, el verde y el amarillo, los colores que distinguen a este país multiétnico. Malvar representa los referentes del paisaje nacional, pero los modifica y los mezcla; hace una afirmación de lo propio latinoamericano y traza nuevas genealogías plásticas que en este caso pasan por Tarsila do Amaral, otra pintora latinoamericana que valora las propuestas que revolucionan el arte. 


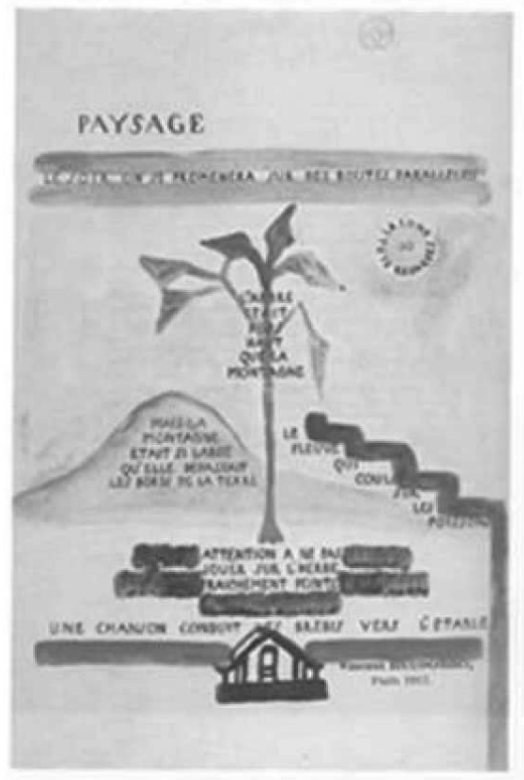

Figura 9. Poema "Paisaje" de Vicente Huidobro pintado por Sara Malvar.

El "paysage" incluye un jardín que se define como "una composición artificial cuyo espacio está separado de su entorno gracias a una reja o cerco que lo circunda" (Schoennenbeck, "Muerte" 257). Etimológicamente, indica una delimitación espacial: "Las raíces indogermánicas de la palabra jardín: gards, geard, garde significan cierre, espacio cercado" (Schoenenbeck, "Muerte" 257) y algo parecido puede decirse "de chortos jardín o huerto en griego, que indica la idea de un terreno cercado. La palabra latina hortus jardín, va por el mismo camino" . La tradición vincula el jardín con el paraíso terrenal, la inocencia, la infancia y el juego" (257), el espacio de paz y de liberación en el que el sujeto se integra a la naturaleza, "el locus amoenus de las criaturas y de las creaturas" (258).

Sara conoce la propuesta del nacionalismo y del realismo en Chile -hay que ser originales y pintar el paisaje propio-, limitación y cerco creativo que ella transgrede en el boceto. El jardín huidobriano convergente con la forma estrófica es un espacio ordenado y ligado a la prohibición, donde no se puede circular ni jugar. Huidobro hace evidente la artificialidad del jardín -"hierba recién pintada"-, planteamiento que resulta una cita paródica del realismo y una sátira el pensamiento artístico anquilosado. Malvar enfatiza el encierro del jardín al pintar una reja verde de líneas 
simétricas y horizontales que lo circunda y lo confirma como un territorio ahogado por las restricciones, las normas académicas y la obligación de imitar la naturaleza nacional: el jardín es una metonimia del encierro existente en el campo literario y plástico chileno.

Existe un paysage abierto y cosmopolita, ilimitado y lúdico que invita a ser leído en forma activa: es un "modelo para armar" que se concibe en un campo cultural autónomo, de múltiples tendencias, que ofrece libertades excepcionales de creación y de expresión. Existe un jardín cerrado y nacionalista, limitado y normado, que invita a ser leído en forma pasiva: es un modelo construido y gestado en un campo cultural con ciertos grados de autonomía, de tendencias artísticas que no han roto con la mímesis realista y que resulta estrecho y reacio a lo nuevo.

Huidobro y Malvar son creadores que transitan entre el paysage y el jardín; cuando están en Francia la interacción en el campo cultural es entre posturas emergentes y residuales. Cuando regresan al país buscan los modos de ampliar los límites del jardín y romper el espacio encerrado de las posturas operantes, el realismo y el nacionalismo. Ambos artistas circulan entre libertad y prohibición, entre autonomía y dependencia, entre modernidad y modernidad periférica. El poema y el poema pintado con sus libertades, transgresiones y parodias, son retratos de la problemática del artista chileno de comienzos del siglo XX.

El retrato resulta otro género en que Sara María demuestra sus convicciones más genuinas. En marzo de 1922 decide hacer uno a "sa maniere" de su amiga Wanda Morla, quien sostiene: "En realidad [Sara] es una modernista en colores y no tiene más pecado que el saber admirar a Cézanne, a Modigliani, a Gauguin, y a Picasso en cuanto a dibujante" (Díaz, Pájaro 123). En otra carta, Wanda detalla el proceso seguido por Sara al pintar: "ella dibuja primero a grandes rasgos en carboncillo, sujeto sobre un papel, enseguida lo calca sobre el yeso, lo retoca intuitivamente sin hacer sombra ni relieve y pinta enseguida. Hay que dejar secar" (Díaz, Pájaro 116).

La artista trabaja en el departamento de Wanda, dos o tres veces por semana y en julio lo termina: "en un piso bajo frente a su caballete, pinta a la témpera un retrato mío que a todos horroriza porque es de colores violentos y con una composición muy osada, un cuello largo 
de gacela a lo Modigliani y unos ojos turquesas [sic] de iniciada" (Díaz, Pájaro 278 ${ }^{18}$.

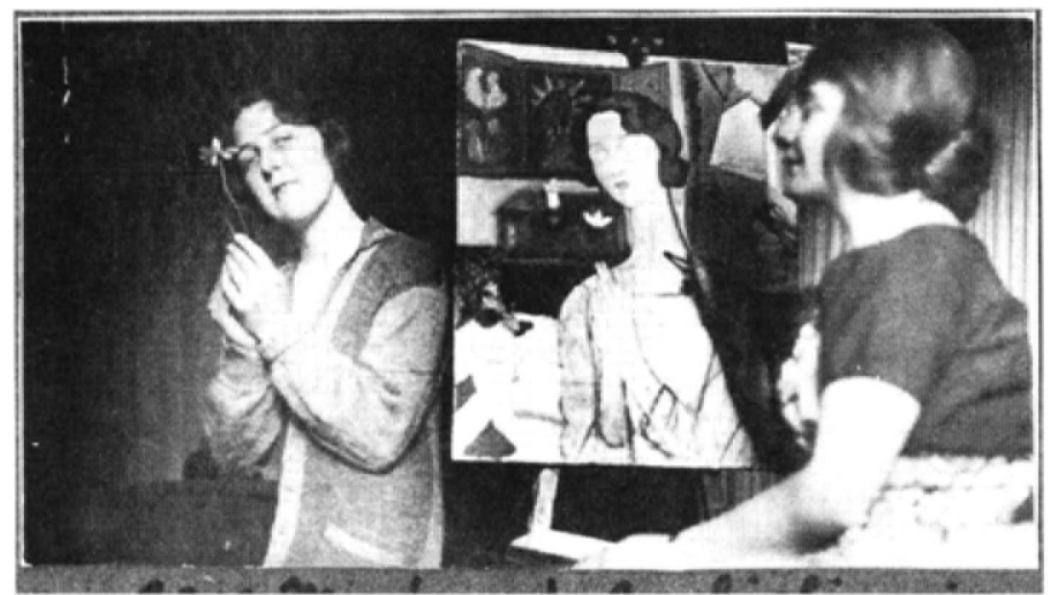

Figura 10. Sara Malvar posando para Wanda Morla en su departamento parisino. Marzo de 1922.

El retrato de Wanda Morla queda asociado para siempre a la memoria de estas dos amigas. En octubre de 1922, José Backhaus lleva el cuadro al Salón de Otoño de París; en el trayecto pasa un momento al taller del escultor español Mateo Hernández, artista que en la misma época que Sara retrata a su amiga, le hace un busto a Wanda también en el departamento de esta.

De regreso del salón, al llegar a su casa en Bellevue, Backhaus se encuentra fatigado a causa de sus problemas cardíacos. Debilitado el jueves cinco de octubre, muere de un ataque al corazón. "No sufrió más que ahogo y se le cayó muerto [a Sara] en el hombro en un momento en que creyendo sentirse mejor se quiso enderezar en la cama. Ahí [Sara] pasó diez minutos con el terrible peso" (Díaz, Pájaro 337) hasta que aparecen las personas que trabajaban en la casa. Al rato, 11:30 de la noche, acude un médico, pero ya no hay nada que hacer.

18 La imagen de Sara Malvar trabajando en casa de Wanda Morla se encuentra en el libro de Wenceslao Diaz, Pajaro... Ver referencias bibliográficas.. 


\section{Palabras finales}

La muerte repentina de José Backhaus deja en una completa desolación a Sara. Wanda Morla y su madre, Luisa Lynch, son las personas que la acompañan en los primeros días y después la acogen en su departamento parisino. El duelo a causa de la muerte de Backhaus, en lo anímico, provoca en Sara una desazón profunda y la pena la lleva a un gran desinterés por el mundo exterior y a un completo extrañamiento respecto de cualquier trabajo productivo que no tenga relación con la memoria del fallecido: para ella, "el mundo se ha hecho pobre y vacío" (Freud, web).

La artista chilena rehúye de todo espacio de sociabilidad, la realidad se le presenta opresiva y absurda, la vida le parece sin sentido y siente el temor de que todo ello durará para siempre, pues la fractura radical no puede colmarse (Raimabult 215). La "inhibición y el angostamiento del yo", como explica Freud, expresan "una entrega incondicional al duelo que nada deja para otros propósitos y otros intereses", experiencia que Sara vive con intensidad al morir Backhaus. La líbido queda encerrada y retraída, no es desplazada sobre otro objeto, de modo que el yo pierde la capacidad de relacionarse y de escoger algún nuevo objeto de amor, pues no habita ningún otro espacio que no sea el duelo amoroso. El retorno de Sara a Chile y su participación en 1924 en las "Notas de Arte" de La Nación, dirigidas por Jean Emar, le cambian la vida y con ello, logra superar sus dolores.

Sara comienza a renacer en Santiago. Su gran inteligencia, la formación recibida en Chile, sus estadías en España y Francia, sus viajes por Italia, su trato con figuras cruciales de la vanguardia, sus visitas a galerías y museos unidas a su práctica artística en el extranjero y su temprana apertura a las nuevas tendencias, le permiten un entendimiento cabal de las transformaciones que emergen en el arte contemporáneo. No resulta extraño entonces que Jean Emar, quien sabe de la artista desde sus primeros tiempos en la academia, estuvo con ella en París y también ha regresado a Chile a comienzos de 1923, la invite a colaborar en una completa labor de puesta al día. Allí Sara terminará de enterrar a Backhaus.

Sara Malvar es de las pocas mujeres de la vanguardia plástica hispanoamericana que, junto a su labor creativa, posee una acabada explicación de las transformaciones operadas en el conjunto del arte, asunto sobre el cual escribe en La Nación. Allí puntualiza los antecedentes de las obras construidas por los fundadores, traza la 
evolución de las tendencias emergentes y señala los ejes que articulan a las distintas expresiones del espíritu nuevo. Al mismo tiempo, percibe con claridad las dificultades que tiene el estudiante de la Escuela de Bellas Artes y el aficionado para entender la revolución artística: ambos poseen una formación inicial proclive a la academia, desconocen los aportes de las tendencias de la vanguardia, se encuentran alejados de las ciudades europeas donde nace esta renovación, carecen de una tradición artística significativa y están insertos en un campo plástico que tiene pocos grados de autonomía.

\section{Referencias bibliográficas}

Aguilar, Gonzalo. Episodios cosmopolitas en la cultura argentina. Buenos Aires, Santiago Arcos editor, 2009.

Berman, Marshall. Todo lo sólido se desvanece en el aire: la experiencia de la modernidad. $4^{\circ}$ ed. México, Siglo XXI, 1991.

Brunner, José Joaquín. “Modernidad”. Términos críticos de sociología de la cultura. Director Carlos Altamirano. Buenos Aires, Paidós, 2002, pp. 173-180.

Cendán, Susana. "Sonia Delaunay y Alfar: Pasajes de una relación singular". Abrente, no. 42-43, 2010-2011, pp. 401-415.

Chadwick, Whitney e Isabelle de Courtivron, editoras. Los otros importantes. Creatividad y relaciones íntimas. Madrid, Cátedra, 1994.

Cortiana, Rino. “Sur la robe elle a un corps ». Poème-manifeste de Blaise Cendrars". https://books.openedition.org/pupo/2529?lang=es

Díaz, Wenceslao. Bohemios en París. Santiago, Ril, 2014.

Pájaro libre como soy. Cartas de Wanda Morla Lynch. Santiago, Ediciones UC, 2013.

Dutching, Hajo. Delaunay. Barcelona, Taschen, 1994.

Emar, Jean. Notas de Arte. (Jean Emar en La Nación. 1923-1927). Estudio y recopilación Patricio Lizama. Santiago, Dibam-Ril Editores, 2003.

Freud, Sigmund. "Duelo y melancolía”. Recuperado de https:// psicovalero.files.wordpress.com/2014/11/sigmund-freudduelo-y-melancolc3ada-1915-1917-t14.pdf 
Godefroy, Cécile. Sa mode, ses tableaux, ses tissus. Paris, Flammarion, 2014.

"Sobre los orígenes de lo simultáneo". Sonia Delaunay. Arte, diseño moda. Madrid, Colección Fundación Thyssen Bornemisza, Colección 2017, pp. 25-55.

Goic, Cedomil. "Espacialismo y dimensión visual en la poesía de Huidobro”. Revista universitaria, no. 82, 2003-2004, pp. 14-20.

Honorato, Paula y Ximena Gallardo. “Copias y Citas”. Copias y Citas. Santiago, Dibam, 2016, pp. 14-34.

Ortiz de Rozas, Marilú. “Eugenia Huici de Errázuriz. la chilena que fue 'árbitro' de todas las elegancias”. El Mercurio. Artes y Letras, 20 marzo 2016, E 2-3.

Pérez, Carlos. "Notas sobre la primera edición de los poemas pintados". Salle XIV. Vicente Huidobro y las artes plásticas. Catálogo. Museo Nacional Centro de Arte Reina Sofía. Madrid, 2001, pp. 35-41.

Raimabult, Ginette. La muerte de un hijo. Buenos Aires, Nueva Visión, 1997.

Ruiz del Árbol, Marta. Sonia Delaunay. Arte, diseño moda. Madrid, 2017.

Sarabia, Rosa. "Una aproximación a los poemas pintados como reflexión del signo artístico". Salle XIV. Vicente Huidobro y las artes plásticas. Catálogo. Museo Nacional Centro de Arte Reina Sofía. Madrid, 2001, pp. 55-65.

Schoennenbeck, Sebastián. "Muerte en el jardín: Paisaje y heterotopía en José Donoso, Mauricio Wacquez y Adolfo Couve”. Revista Laboratorio, no. 15, diciembre 2016. Web.

"Paisaje, nación y representación del sujeto popular. Visiones de un Chile imaginado". Aisthesis, no. 53, 2013, pp. 73-94.

Subercaseaux, Bernardo. "Literatura, nación y nacionalismo". Revista Chilena de Literatura, no. 70, abril 2007, pp. 5-37.

Vyvyan, Patrick. “Cronología y Entorno”. Catálogo a la exposición de Henriette Petit. Museo Nacional de Bellas Artes, Santiago, 1997, pp. 21-40.

Yurkievich, Saúl. "Los avatares de la vanguardia”. Revista iberoamericana, no. 118-119, enero-junio 1982, pp. 51-56. 